\title{
Fungi in Grapes Cultivated in Brazil Used for Juice Production
}

Larissa Souza Ferranti (I,II), Maria Helena Pelegrinelli Fungaro (II), Marta Hiromi Taniwaki (I), Daniele Sartori (II), Fernanda Pelisson Massi (II), Helena Viaro (II), Josué Silva (II), Rafael Elias Silva Penha (II), Beatriz Thie lamanaka (I)

(I) ITAL - Food Technology Institute (Av. Brasil, 2880 - CEP 130.70-178 Campinas-SP), (II) UEL - Stadual University of Londrina (Rodovia Celso Garcia Cid, Km 380 - Campus Universitário, CEP 86057-970, Londrina)

\section{Resumo}

Grape production has become an important activity in Brazil, mainly due to the sustainability of small vineyards, resulting in more employment in the grape processing industry. Although there is an effort to control fungal contamination in food, the toxigenic fungi are present in nature and occur regularly in food such as cereals, fruits and nuts. The three main genera of toxin production in foods are: Aspergillus, Fusarium and Penicillium.

Aspergillus section Nigri are commonly found in food, while some of its species are able to produce mycotoxins, such as ochratoxin and fumonisin. The objective of this study was to identify the mycobiota of grapes for juice production, in different regions of Brazil. Samples were collected from the states of Paraná (10), Rio Grande do Sul (10) and Pernambuco (9). The samples were plated on agar Dichloran Rose Bengal Chloramphenicol (DRBC) and incubated at $25^{\circ} \mathrm{C}$ for 7 days. The identification was performed by the morphological characteristics. A total of 29 samples of grapes (Bordo, Isabel and Isabel precoce), all for juice production, were analyzed. All samples showed high fungal contamination (100\%). The most common genera found in these samples were A. section Nigri, present in $82.75 \%$ of the samples, Cladosporium sp. (62.07\%), Penicillium. sp. (58.62\%) and Fusarium sp. and Alternaria sp. (51.72\%). In addition there was a high rate of infection with yeasts (100\%).However, the percentage of 
infection by each of these fungi varied from region to region. Samples from Paraná showed an average infection by Aspergillus section Nigri of 9.6\%; Cladosporium sp. 70.9\%; Penicillium sp. 12.9\%; Fusarium sp. 21.6\% and Alternaria sp. 0\%. Samples from Rio Grande do Sul obtained fungal infection by the same species of $8.8 \% ; 4.6 \% ; 2.5 \% ; 6.1 \%$ and $30.6 \%$ and Petrolina of $41.4 \% ; 52.2 \% ; 28.9 \% ; 4.7 \%$ and $41.33 \%$ respectively.

Palavras-Chave: Fungi, Grape, Aspergillus Agência de Fomento: Fapesp 